Research Article

\title{
3D Printing in Construction: Current Status, Implementation Hindrances, and Development Agenda
}

\author{
Xin Ning $\mathbb{D},{ }^{1}$ Tong Liu $\mathbb{D},{ }^{1}$ Chunlin $W u \mathbb{D}^{2,3}$ and Chao Wang ${ }^{4}{ }^{4}$ \\ ${ }^{1}$ School of Investment and Construction Management, Dongbei University of Finance and Economics, Dalian 116025, China \\ ${ }^{2}$ Department of Behavior and Operation Management, School of Economics and Management, Beihang University, \\ Haidian District, Beijing 100191, China \\ ${ }^{3}$ Beijing Key Laboratory of Emergency Support Simulation Technologies for City Operations, Beihang University, \\ Haidian District, Beijing 100191, China \\ ${ }^{4}$ Bert S. Turner Dept. of Construction Management, Louisiana State University, Baton Rouge, LA, USA
}

Correspondence should be addressed to Chunlin Wu; wuchunlin@buaa.edu.cn

Received 10 December 2020; Revised 22 March 2021; Accepted 26 March 2021; Published 7 April 2021

Academic Editor: Zhigang Zhang

Copyright (c) 2021 Xin Ning et al. This is an open access article distributed under the Creative Commons Attribution License, which permits unrestricted use, distribution, and reproduction in any medium, provided the original work is properly cited.

3D printing (3DP) is regarded as an innovation that contributes to automation in civil engineering and offers benefits in design, greenness, and efficiency. It is necessary to objectively analyze the current status and challenges associated with 3DP and identify future research directions to properly understand its construction applications. Previous research has focused more on the technical dimension of 3DP; however, the nontechnical dimension of the technology may hinder its implementation and thus must be paid particular attention to. This study presents a systematic review of the existing literature from both technical and nontechnical dimensions by combining quantitative and qualitative studies. The quantitative study was conducted using scientometric methods. The qualitative study analyzed information, including the technical research status and nontechnical challenges and trends. Two aspects of technical research status are presented, including materials and processes. In addition, nontechnical challenges and trends from the economic, environmental, social, and legislative aspects are proposed. This study provides a comprehensive agenda to advance 3DP in construction and proposes research interests, challenges, and future topics. It is intended to help construction practitioners systematically master existing processes and materials and assess the application degree and necessity of 3DP.

\section{Introduction}

3D printing (3DP), commonly known as additive manufacturing (AM) [1], is a layered material joining process that is based on $3 \mathrm{D}$ model data to manufacture various structures and complex geometric shapes without using any tooling, dies, or fixtures [2-4]. With its potential for automation, formwork elimination, construction waste reduction, and improvement of geometrical precision, 3DP shows a lot of promise for applications in the construction industry. The technical dimension mainly includes the printing materials and printing processes that are essential for developing this innovative technology [5], and current research mainly focuses on material properties [6] and process applicability [7]. However, as understandings of the technology have developed, some economic and environmental issues have emerged [8]. For example, the impact on the environment and uncertain cost of materials have a significant influence on the sustainable development of 3DP in construction. The technical dimension is a core factor of 3DP, but the nontechnical dimension must also be considered. This study not only summarizes the latest research advances in the technical dimension but also presents the challenges and trends associated with 3DP from the economic, environment, social, and legislative perspectives (collectively referred to as the nontechnical dimension) to ensure a systematic and comprehensive review.

Over the past few decades, many studies on 3DP innovations have been conducted to address the technical dimension. In 1986, Charles Hull, an American scientist 
known as the father of 3DP, developed the first commercial 3D printing machine [9]. The experimental application of 3DP in the construction industry began in the late 1990 s when Pegna proposed using cement-based materials in conjunction with 3DP [10]. The existing research on 3DP focuses on advanced materials (e.g., cementitious materials $[1,11,12]$, polymer materials [13-15], and metal materials [16-18]), processes (e.g., contour crafting [19], D-shape [20], and concrete printing $[6,7])$, and implementation methods (e.g., off-site/on-site fabrication [21], hybrid techniques [22], and multiple materials [22]), which allow it to be used in the construction industry. Construction applications include novel forms [22], topology optimization [23], customized parts [22], and in-situ repair [23, 24]. There have also been different applications in different countries, such as the WinSun offices in Dubai [25] and the Canal House in Amsterdam, Netherlands [18]. To enable researchers to systematically understand the research and application of 3DP in construction, several review articles are summarized in Table 1.

The review articles listed in Table 1 mainly address the issues of processes, materials, and cases. However, to encourage more widespread use of $3 \mathrm{DP}$ in construction, nontechnical dimensions, such as cost, energy consumption, and health issues, must also be thoroughly explored because they will become important indicators affecting the application of 3DP in more mature stages of the technology in the future. Concerning the review method, qualitative and quantitative studies (e.g., scientometric analysis [31] and text mining [32]) are adopted separately. The qualitative study is a traditional review method that refers to in-depth discussion and analysis based on many manual literature studies or initial bibliometric analysis to summarize the state-of-theart review of a specific domain [33]. However, to obtain a quantitative and more accurate study of science and technology, the scientometric analysis should be applied [34]. Scientometric analysis is data-driven and can objectively identify the laws of the scientific domain. Once the laws are established, science mapping is performed to show the laws via a graph [35]. Most of the previous review articles adopted a qualitative study and focused on the introduction of a certain aspect according to the experience. This resulted in unclear research subjects, uneconomic research content repetition, and inadequate scientific quantitative sorting. Although several of the reviews used some specific functions of measurement, there is an overall lack of follow-up on the in-depth qualitative analysis. To solve these problems, this study adopts a combination of quantitative and qualitative studies, which not only guarantees the objectivity of the study but also provides a more comprehensive and in-depth review of $3 \mathrm{DP}$.

To perform a holistic and systematic review, the structure of this paper is as follows. First, the research methodology is introduced, including quantitative and qualitative studies. Second, the tool CiteSpace is used to conduct a science mapping approach and identify the influential journals and keywords in the domain of 3DP in construction by the quantitative study. Then, the qualitative study is addressed from both the technical dimension (processes and materials) and nontechnical dimension (environmental, economic, social, and legislative aspects). Finally, conclusions, implications, and limitations are stated. This study serves as a summary of scientific insights and directives to assist researchers and practitioners with understanding further applications of 3DP in the construction industry, which not only informs researchers of the latest progress but also proposes some constraints to the use of 3DP in practical application.

\section{Research Methodology}

The review process begins with a two-step literature review quantitative study (data collection and visualization). Then, a qualitative study is conducted from two dimensions (technical research status and nontechnical challenges and trends). As shown in Figure 1, these two studies form the complete review process.

\subsection{Quantitative Study}

2.1.1. Data Collection. Based on the Web of Science (WOS), a core collection database comprising the most influential journals in the world, this study included an advanced search of journal articles written in English by excluding book reviews, editorials, and conference papers. This study was conducted under the assumption that the most comprehensive and high-quality information and reviews in the field of construction are provided in journal articles [36]. Thus, this review only analyzed journal articles. After a preliminary analysis, the following retrieval codes in the WOS core set were used:

TS = ("3D print $*$ " OR "three-dimensional print $*$ “OR "additive manufacture*" OR "rapid prototyping" OR "digital fabricat*" OR "digital construct*" OR "additive construct*") AND SU = (Construction and Building Technology).

A total of 347 records were retrieved using these codes. In accordance with the process shown in Figure 1, the resulting 347 records were further refined. Articles not related to construction were excluded based on titles, abstracts, and keywords. After these refinements, 285 records remained that were published over the last nine years from 2012 to 2020 . This literature sample is illustrated in Figure 2 and ordered by the publication year.

2.1.2. Scientometric Analysis and Visualization. This study conducted scientometric analysis and visualization using the literature sample in an appointed scientific knowledge domain according to the science mapping approach [37] via CiteSpace software. The science mapping approach is a process that describes the scientific domains in structured terms for conceptual, intellectual, and social dimensions and constructs visual maps. This study focused on journal sources and author analyses to identify the most influential journals utilizing 3DP in construction. A keyword analysis was also conducted to reveal emerging research interests. 
TABLe 1: Previous review literature of 3DPT in construction.

\begin{tabular}{|c|c|c|}
\hline Literature & Review contents & Review method \\
\hline $\begin{array}{l}\text { Perkins and } \\
\text { Skitmorev [21] }\end{array}$ & $\begin{array}{c}\text { Three processes (contour crafting, D-Shape, and concrete printing); advantages and } \\
\text { limitations of 3DP }\end{array}$ & Qualitative study \\
\hline & Definition and characteristics of 3DP; history, challenges, and future of 3DP & Pit \\
\hline Labc & $\mathrm{Ma}$ & $\begin{array}{r}\text { Systematic } \\
\text { stu }\end{array}$ \\
\hline Bos & $\begin{array}{r}\text { 3D concrete prin } \\
\text { char }\end{array}$ & Qualitativ \\
\hline Tay & $\begin{array}{r}\text { State-of-the-art technologies for 3DP in const } \\
\text { directions and }\end{array}$ & $\begin{array}{r}\text { Systemat } \\
\text { s }\end{array}$ \\
\hline Cam & $\begin{array}{r}\text { Processes and materials; potential ady } \\
\text { methods }\end{array}$ & Qualitative \\
\hline $\begin{array}{l}\text { Ghaffar } e \\
{[29]}\end{array}$ & $\begin{array}{c}\text { Innovation, socioeconomic and environmental impacts, and materials feed stocks for 3DP in } \\
\text { construction }\end{array}$ & Qualitati \\
\hline Siddika et al. [30] & $\begin{array}{l}\text { The technical, socioeconomical, and environmental aspects related to 3DCP; the technology, } \\
\text { guidelines, applications, challenges, and prospects of future research of } 3 \mathrm{DCP}\end{array}$ & Qualitativ \\
\hline
\end{tabular}

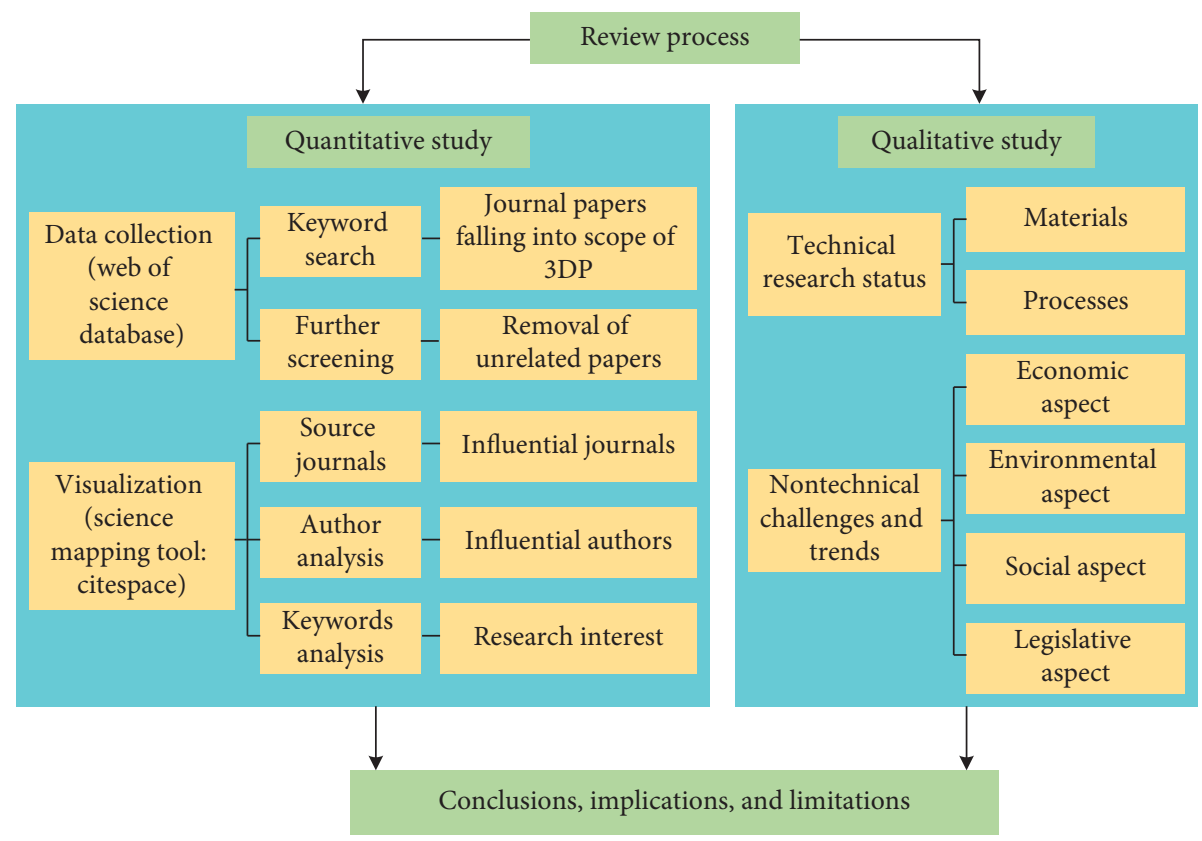

FIGURE 1: Review process.

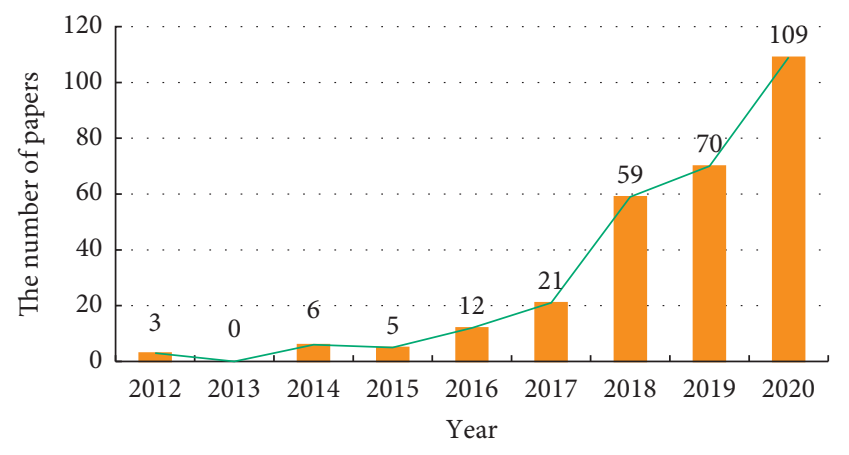

FigURE 2: Literature sample in terms of the year of publication from 2012 to 2020 .
2.2. Qualitative Study. Based on the prior quantitative analysis of the literature [38], a follow-up qualitative analysis was conducted to deeply evaluate the research on 3DP applications in construction. Based on keyword analysis, the research interests of the qualitative study were obtained. The primary purpose of a qualitative study is to identify current materials and processes. This part proposes the technical factors related to the application of 3DP and theoretically analyzes the research directions of 3DP. The challenges and trends that 3DP will encounter in practice in the construction industry in the future are also discussed from the economic, environmental, social, and legislative aspects. 


\section{Scientometric Results and Discussion}

The results of the quantitative study are provided, including source journals, authors, and keyword analyses. Two structural metrics were derived, including frequency and betweenness centrality. The frequency represents the number of journals, authors, and keywords that appeared. The betweenness centrality is the ratio of the total number of the shortest paths between two nodes that pass given nodes to the total number of all shortest paths [38] (hereafter called centrality), which can be obtained through the processing in the CiteSpace software. Through several adjustments made in advance, the threshold was set as the "Top 50" (the top 50 articles in each time increment were extracted during data processing to generate the final network) in this study.

3.1. Source Journals. A source journal is defined as the journal in which an identified article was published [38]. This study identified the published articles on 3DP in construction in source journals that are in line with the statistics of the WOS core collection database, as shown in Figure 3.

Clearly, four journals, namely Construction and Building Materials (84 records), Automation in Construction (54 records), Cement and Concrete Research (33 records), and Cement and Concrete Composites (20 records), published significantly more 3DP related articles than others. Automation in Construction covers the management of the entire life cycle of construction, while Construction and Building Materials is more focused on construction materials and technologies. Cement and Concrete Research and Cement and Concrete Composites mainly introduce research achievements related to cement and concrete. At present, the research on 3DP mainly focuses on increased understanding of materials and processes. Construction and Building Materials has published the most articles in the literature sample. Because 3DP is a technology based on digitalization and automation [39], articles from Automation in Construction also account for a large portion of the published literature. As the material used in 3DP is mainly concrete, there have also been some articles published in Cement and Concrete Research and Cement and Concrete Composites.

Additionally, Tan is the researcher who has the greatest number of publications in the field of 3DP in construction in WOS. And Tan, Weng, and Li et al. jointly published many articles related to 3DP and achieved a lot of significant research progress. For example, they studied the effects of the thixotropic behavior of materials and printing parameters on interlayer bond strength [40] and proposed a synchronized method to significantly improve interlayer bond strength [41]. They studied the effect of nozzle rotation on material distribution in printed filaments [42] and simulated material deformation in printed filaments [43]. And a buildability model was proposed for the first time and verified experimentally [44].

3.2. Keyword Analysis. As a core part of the content of published studies, keywords can be analyzed to describe the research interest within a given domain $[31,38]$. In this review, a keyword analysis was conducted to understand the structural changes in the body of research and identify current applications of 3DP in construction. The keyword term sources in this review were evaluated from the title, abstract, keywords, and keywords plus. Synonymous keywords were combined. The keywords and their relationships are shown in Figure 4. Note that the node size refers to the frequency of the keywords in the dataset, and the link between the nodes represents the cooccurrence of the keywords.

The keywords shown in Table 2 were divided into the technical and nontechnical dimensions according to their characteristics.

3.2.1. Technical Dimension. 3D printed materials and their properties are significant research interests. Cementitious materials are one of the most common building materials at present [45]. The keywords related to materials include concrete, mechanical property, performance, rheological property, strength, fresh, behavior, extrusion, cementitious material, geopolymer, thixotropy, hardened property, compression test, buildability, slag, bone, and interlayer boning. 3D printed construction materials should have good mechanical properties to obtain better printability, including pump ability, extrudability, and buildability [31]. For example, the fresh rheological properties of cementitious materials are crucial to their applicability in 3DP in construction, as these properties can exert a considerable influence on the pump ability and buildability of the printing mixture [46]. Liu et al. [47] proposed a hybrid design method to optimize the rheological properties of printable materials.

The research on 3DP processes is another issue that needs to be addressed. 3DP is also known as AM [1], which is widely used in the manufacturing industry with different processes. When applied to the construction industry, the typically used process is concrete printing. Currently, structural integrity and anisotropy properties, postprocessing, reinforcement in structures, and printed cantilever structures are the key problems in the process aspect that need to be addressed.

3.2.2. Nontechnical Dimension. The construction group comprises the keywords construction, design, digital fabrication, automated construction, and fabrication. Digital fabrication is an innovative technology that can help to expand the boundaries of construction [48]. 3DP is an attempt to implement digital fabrication in practice. It can serve as a support technology to provide a better understanding of design and construction during the design phase when combined with building information modelling (BIM) [49], which is defined as a shared knowledge resource of facility information that provides a solid basis for decisionmaking over the life cycle. Weng et al. [50] explored the method of 3DP automatic path design, which realized the integration of 3DP and BIM. The printing path is automatically designed after obtaining information from BIM. 


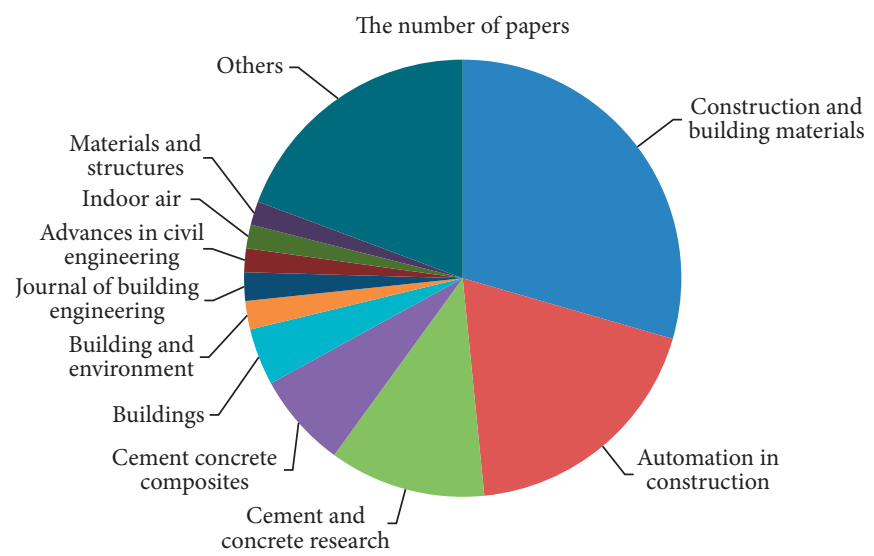

FIGURE 3: Source journals conforming with the statistics of the WOS core collection database.

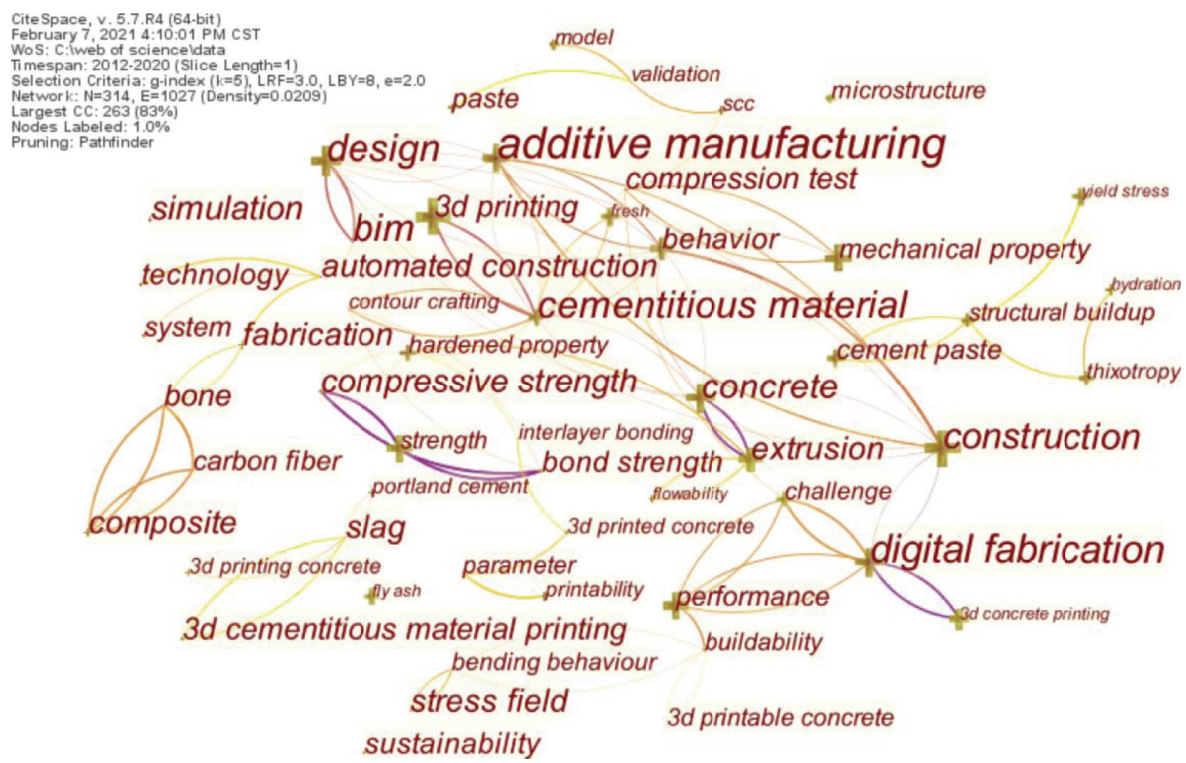

FIGURE 4: Visualization of keywords based on cooccurrence network.

The construction industry has a considerable environmental impact in the world. As an innovative process, 3DP is considered to have huge potential to overcome some of the problems associated with traditional construction [51]. However, there are still some challenges associated with the incorporation of 3DP from the sustainability and legislative perspectives. To apply 3DP in construction, sustainability and legislative applicability must be achieved.

\section{Technical Research Status}

After a preliminary understanding of the influential journals was reached, the three main interests from the aspects of materials, processes, and construction were extracted from the keywords. An in-depth qualitative analysis was undertaken to summarize the previous research that mainly focused on 3DP materials and processes.

4.1. Materials. Currently, most of the materials used for 3DP are cementitious materials, polymer materials, and metal materials [20, 23]. The advantages, limitations, and applications of these three materials are provided in Table 3.

In the construction industry, various materials are often combined, such as steel and concrete. Because the performance of many materials has individual characteristics, the structure of the building should have several characteristics to be able to support the designed load. New cementitious and metal materials developed for 3DP applications may utilize traditional materials or may develop entirely new materials. At present, many new materials have been developed, such as sustainable cement-based composites [52], sustainable magnesium potassium phosphate cement paste [53], and geopolymer composites [54]. In the future, integrating different material properties [55] and adopting multiple methods for material improvement will be one of the research emphases. In one approach, the properties of materials and processes complement each other. To improve the process properties, the material properties should be improved as much as possible. In the other approaches, researchers introduce and evaluate new materials in new 
TABLE 2: Keywords ranked according to frequency and centrality.

\begin{tabular}{lccc}
\hline Keywords & Frequency & Keywords & Centrality \\
\hline Construction & 94 & Automated construction & 0.35 \\
3D printing & 91 & BIM & 0.32 \\
Concrete & 77 & Design & 0.31 \\
Mechanical property & 55 & Cementitious material & 0.29 \\
Performance & 52 & Hardened property & 0.24 \\
Additive manufacturing & 52 & Fabrication & 0.22 \\
Design & 49 & Mechanical property & Behavior \\
Digital fabrication & 47 & Compression test & 0.21 \\
Rheological property & 44 & Buildability & 0.21 \\
Strength & 43 & Slag & 0.21 \\
Fresh & 41 & Construction & 0.20 \\
Behavior & 37 & Digital fabrication \\
Extrusion & 36 & Performance \\
3D concrete printing & 33 & Additive manufacturing \\
Cementitious material & 30 & Bone & 0.20 \\
Geopolymer & 30 & Interlayer boning \\
Thixotropy & 27 & 0.19 \\
\hline
\end{tabular}

TABle 3: Current state of the art of materials.

\begin{tabular}{|c|c|c|c|}
\hline Materials & Benefits & Limitations & Applications \\
\hline $\begin{array}{l}\text { Cementitious } \\
\text { materials }\end{array}$ & $\begin{array}{l}\text { Mass customization } \\
\text { No formwork required } \\
\text { Less labor required }\end{array}$ & $\begin{array}{c}\text { Layer-by-layer appearance } \\
\text { Anisotropic mechanical properties } \\
\text { Poor interlayer adhesion } \\
\text { Limited building size } \\
\text { Limited number of printing methods } \\
\text { Limited customized concrete mixture design }\end{array}$ & Infrastructure and construction \\
\hline Polymer materials & $\begin{array}{c}\text { Fast prototyping } \\
\text { Mass customization } \\
\text { High economic efficiency } \\
\text { Complex structures } \\
\end{array}$ & $\begin{array}{l}\text { Poor and anisotropic mechanical properties } \\
\text { Limited selection of polymers }\end{array}$ & Infrastructure and construction \\
\hline Metal materials & $\begin{array}{l}\text { Multifunctional optimization } \\
\text { Mass customization } \\
\text { Improved material utilization } \\
\text { Fewer assembly components } \\
\text { In-situ repair }\end{array}$ & $\begin{array}{l}\text { Dimensional inaccuracy and poor surface finish } \\
\text { Additional postprocessing } \\
\text { Limited selection of alloys }\end{array}$ & Medium-scale components \\
\hline
\end{tabular}

applications. For example, Weng et al. [56] studied a 3D printable fiber-reinforced cementing composite for largescale printing and verified its printability and fire resistance at high temperatures. The ability to finely tune materials according to the requirements of each application will determine the success of 3DP in construction and will require the utilization of multiple materials within a single printing process to create material property gradients [20].

4.2. Processes. Contour crafting (CC) [2, 21, 57], D-shape $[2,21,57]$, concrete printing $[2,21,58]$, and shotcrete $3 \mathrm{D}$ printing [59-61] are the primary processes for large-scale structural 3DP. The current state of the art of these processes is shown in Table 4.

Originally, 3DP was designed to produce low-volume, small, complex products and was known as rapid prototyping [26]. Rapid prototyping has, thus far, only been used within the architectural fields to produce complex scale models of buildings $[10,62]$. Over the years, several large- scale 3DP construction and applications have been developed based on the principle of rapid manufacturing, which provides construction automation, maximum design freedom, and the potential to build additional functions into the structure [63]. For example, Zhang et al. [64] proposed a 3DP system, which used multiple mobile robots to carry out large-scale and parallel 3DP on concrete structures. Lim et al. [65] used a new adaptive membrane template for 3DP, which demonstrates great potential for the 3DP of nondevelopable curved panels. Although there are many examples of 3DP at present, there are still many practical challenges to be solved. The identification and evaluation of these challenges will form the main research directions in the future. In large-scale in-situ construction projects, owing to the processing of a large filament cross section and high printing speed, many issues related to the printing process must be addressed. Such issues include configuration of the printing head, determination of the printer kinematics, and the printing strategy itself [39]. Tay et al. [28] suggested that the ultimate hardened printing product and mechanical 
TABle 4: Current state of the art of 3DP processes.

\begin{tabular}{|c|c|c|c|c|}
\hline Processes & Originators & Characteristics & Advantages & Limitations \\
\hline \multirow{4}{*}{$\begin{array}{l}\text { Contour } \\
\text { crafting }\end{array}$} & \multirow{4}{*}{$\begin{array}{l}\text { Dr. Khoshnevis of the } \\
\text { University of Southern } \\
\text { California }\end{array}$} & Extrusion-based & $\begin{array}{l}\text { Good surface quality of printed } \\
\text { components }\end{array}$ & Limited vertical extrusion; \\
\hline & & Crane-mounted & Improved manufacturing & \multirow{3}{*}{$\begin{array}{l}\text { The complexity of the initial } \\
\text { formwork and trowel system. The } \\
\text { limitation of the object size and } \\
\text { shape }\end{array}$} \\
\hline & & On-site & & \\
\hline & & $\begin{array}{l}\text { Print resolution with } \\
13 \mathrm{~mm}\end{array}$ & A wide selection of materials & \\
\hline \multirow{4}{*}{ D-shape } & \multirow{4}{*}{ Enrico Dini } & Powder-based & $\begin{array}{l}\text { Any materials that resemble sand } \\
\text { can be used; }\end{array}$ & \multirow{4}{*}{ Signal material type } \\
\hline & & Gantry-based & Little waste is produced; & \\
\hline & & $\begin{array}{l}\text { Off-site (on-site under } \\
\text { appropriate amount of } \\
\text { modification) }\end{array}$ & $\begin{array}{l}\text { Slight processing is required in } \\
\text { production; }\end{array}$ & \\
\hline & & $\begin{array}{l}\text { Print resolution with } \\
4-6 \mathrm{~mm}\end{array}$ & $\begin{array}{l}\text { The final products can be } \\
\text { resembled natural stones }\end{array}$ & \\
\hline \multirow{5}{*}{$\begin{array}{l}\text { Concrete } \\
\text { printing }\end{array}$} & \multirow{5}{*}{$\begin{array}{l}\text { The research team of the } \\
\text { Loughborough } \\
\text { University }\end{array}$} & Extrusion-based & $\begin{array}{l}\text { Optimization of material } \\
\text { utilization and site work }\end{array}$ & $\begin{array}{l}\text { Additional deposition equipment } \\
\text { causing extra operation }\end{array}$ \\
\hline & & Gantry-based & $\begin{array}{l}\text { Production of neoteric internal } \\
\text { and external finishes }\end{array}$ & \multirow{4}{*}{$\begin{array}{l}\text { A secondary support structure } \\
\text { needs to be removed during } \\
\text { postprocessing }\end{array}$} \\
\hline & & Off-site (on-site under & Reduction in the details of the & \\
\hline & & & & \\
\hline & & $\begin{array}{l}\text { Print resolution with } \\
4-6 \mathrm{~mm}\end{array}$ & $\begin{array}{c}\text { Provision of greater design } \\
\text { freedom }\end{array}$ & \\
\hline \multirow[b]{2}{*}{$\begin{array}{l}\text { Shotcrete } \\
\text { 3D printing }\end{array}$} & Technische Universität & Spray-based & $\begin{array}{c}\text { An easier approach in vertical and } \\
\text { overhead construction; }\end{array}$ & $\begin{array}{l}\text { Low dimensional accuracy of } \\
\text { sprayed profiles }\end{array}$ \\
\hline & Braunschweig & $\begin{array}{l}\text { Gantry-based } \\
\text { Off-site } \\
\text { Print resolution with } \\
5 \mathrm{~mm}\end{array}$ & $\begin{array}{l}\text { Good adherence of the sprayed } \\
\text { material with a certain thickness } \\
\text { on vertical and overhead substrates }\end{array}$ & $\begin{array}{l}\text { Irregular cross sections of the } \\
\text { sprayed structure }\end{array}$ \\
\hline
\end{tabular}

behavior of the process are the key future research directions.

\section{Nontechnical Challenges and Trends}

Further research on the application of 3DP in construction is still required; however, many research challenges exist, and further experiments need to be conducted. There are also many potential applications in the future. Nontechnical challenges and trends are mainly expounded from the economic, environmental, social, and legislative perspectives.

\subsection{Economic Challenges and Trends}

5.1.1. Mass Customization. Ngo et al. [3] suggested that mass customization is the main advantage of 3DP in construction. However, the demand for mass customization is still insufficient in construction [26]. Owing to the characteristics of fixity and the diversity of available construction products, the construction industry has always been regarded with a low degree of customization [26]. A decrease in the cost of printing will help the technology have a place in practical applications. Compared with the mass customization of building components, personalized customization of full-size buildings will have more development prospects.
3DP has huge design potential and could be used to construct buildings that require complex shapes [66] or are in special environments, such as the components of lunar outposts [67]. In the future, with the popularization of this technology, private consumers could also customize their own houses. $3 \mathrm{DP}$ also has great development potential in the field of personalized interior decoration.

5.1.2. Financial Performance over the Life Cycle. Cost is one of the challenges of $3 \mathrm{DP}$ in construction. However, it is unclear whether 3DP will lead to a cost increase or reduction. The cost increase associated with using 3DP as compared to traditional technology mainly involves two conditions. The first condition is the time cost. To obtain better surface finish quality, more time is required, thus increasing the time cost. The second condition is the optimization cost. Any optimization process will increase the cost via additional design work, and the structure may become unnecessarily complex [16]. However, from the perspective of cost structure, the three most recognized costs in construction are materials, manpower, and facilities. 3DP will reduce construction costs owing to its automation process, which reduces the labor demand and labor cost $[26,32]$. Moreover, 3DP can reduce the costs associated with site optimization and remedial work, and the price of $3 \mathrm{D}$ printers has also dropped. Therefore, to measure whether 
3DP can reduce costs, it is necessary to evaluate the financial performance of construction products in the whole life cycle [28]. To assess the life cycle cost of 3DP in raw materials and printing systems $[16,26]$, further empirical research is required to determine how to select theoretically efficient and economical technologies [26, 32]. Weng et al. [68] performed a comparative study of economic cost via extrusionbased 3DP and a precast approach, which revealed that it could significantly reduce the overall cost.

5.2. Environmental Challenges and Trends. Although a few studies have clearly pointed out that 3DP can improve the environment [30], studies on the impact of 3DP on the environment are insufficient. It is necessary to evaluate the selection of environmental indicators in the application of any new technology. For example, indicators such as energy consumption, carbon emissions, and the use and production of toxic substances [69] are selected for evaluation. One of the future research trends is using life cycle assessment (LCA) to evaluate the environmental impact of 3DP. LCA is an approach that helps decision makers choose a particular scheme among several options based on various environmental performance indicators and provides a reference for decision makers to design and optimize schemes [70]. LCA is one of the most widely used tools for building environment assessment [71]. For example, Alhumayani et al. [72] used LCA to explore the environmental impact of different building materials and processes in large-scale 3DP construction. Han et al. [73] attempted to use LCA to assess the environmental impact and economic benefits of recycled 3DP buildings.

As an evaluation method, LCA involves the collection, processing, and analysis of massive amounts of data, which is time-consuming and laborious. Therefore, information software tools, such as BIM, are required to support LCA. BIM is a construction management method based on the life cycle with a wide range of stages, including planning and scheduling [30]. BIM is typically used for $3 \mathrm{D}$ visualization $[74,75]$, such as the maintenance and conservation management of the built heritage [76]. Currently, relevant research has been performed on the building environmental impact assessment method called BIM-LCA, and the evaluation of the impact of 3DP on the environment has shown that it can improve efficiency and accuracy.

\subsection{Social Challenges and Trends}

5.3.1. Health and Safety. One of the challenges of applying $3 \mathrm{DP}$ in construction is effective management of emissions because there is potential hazard associated with construction personnel's health and safety. In theory, there are many similarities between construction and manufacturing industry. 3DP uses fewer resources and materials to produce less waste, but it also creates new potential hazards. These hazards mainly include the discharge of harmful substances, which can cause harm to human health and the environment, and their impacts on the final products are unknown. Additionally, 3DP uses different materials than traditional construction, and new materials are constantly in development. It is impossible to determine whether these unconventional materials are toxic or cause various occupational health problems [69]. In practice, future practitioners who want to promote $3 \mathrm{DP}$ should continue to study the health and safety implications. Two aspects should be studied. The first is the identification of potential impacts to the raw materials used in the printing process and the final product. The second is the development of consistent health and safety standards, such as emission and toxicological contact control methods [77].

5.3.2. Sustainable Employment. The construction industry has a great influence on the national economy and provides many employment opportunities [5]. New technologies tend to create new jobs [78]; however, the implementation of 3DP in construction will potentially affect basic manual tasks [5]. Labor force participation rates are expected to fall as these jobs are replaced by automation. Studies have shown that 3DP may lead to a reduction in employment opportunities unless workers can find a way to remain relevant with the new technology [28]. In addition, as technology makes jobs more specialized, the number of low-skilled workers is likely to decline while the number of professional workers increases. Therefore, how to achieve sustainable employment is a key issue. On the one hand, existing employees working with traditional methods could be retrained to reduce unemployment. On the other hand, new employment opportunities can be provided for relevant technical personnel, such as programming.

\subsection{Legislative Challenges and Trends}

5.4.1. Intellectual Property. Despite its potential advantages, $3 \mathrm{DP}$ has not yet reached its full capacity in the construction industry. 3DP is not a technology that can fully replace traditional building methods, at least for now. Legislation is always behind innovation. While many researchers and companies are reaping the benefits of $3 \mathrm{DP}$, there is another group of people who are struggling with intellectual property protection. This hinders the application of 3DP in the construction industry [79]. As mentioned earlier, the task of developing a uniform 3DP standard is challenging because of the diversity of printers, materials, and processes. From an intellectual property perspective, there are laws and regulations that protect new inventions and inventors. However, the advent of 3DP, which has spawned a 3DP market and downloadable open-source projects, is a challenge to intellectual property. Fundamental changes may arise in the way of patent application and protection because of the emergency of 3DP. One of the future research directions will be the establishment of intellectual property protection principles for $3 \mathrm{D}$ design models. For example, researchers could embed information in the spectrum and internal structures to encrypt it [80].

5.4.2. Construction Standards. Although 3DP is widely used in several industries, its application in architectural fields is still in the preliminary conceptual stage. There are no standardized building principles or examples, which is one of the challenges facing 3DP [16]. Currently, there are 


Current research
areas

FIgURE 5: Framework for the future development of 3DP in construction.

numerous materials, equipment, and processes, but no clear requirements for materials, processes, calibration, tests, and document format standards. In the long run, this is not conducive to the quality assurance of 3DP products. For example, parts printed using certain grades of materials may lack the ability to resist environmental impacts and fail under high stress [29]. Furthermore, inadequate online detection in the printing process [81] requires further research. Therefore, it is necessary to create a full-scale series of design criteria, construction guidelines, and standard practices for 3DP in construction [80], which would reflect industry knowledge, help stimulate research, and promote implementation. In the future, the establishment of material standards, manufacturing processes, and structural designs will be essential before printed components can be used in buildings and the construction industry [14].

Additionally, the situation of the 3DP construction project is complicated and the shape is unique, so the preparation of tendering documents for the project needs more consideration. Traditional tendering mode may no longer be applicable to 3DP construction projects, and BIMbased tendering mode will become the development direction in the future. BIM has the characteristic of visibility, coordination, simulation, and optimization, which can reduce errors, save time, improve efficiency, and conduct dynamic supervision. Tenderers can make use of the BIM model provided by the tenderee to prepare the construction plan and construction organization design of the tender offer in a short time, which can reduce the communication barrier between the tenderee and the tenderer to a certain extent and reduce the difficulty of manual operation and cost expenditure. However, the BIM-based tendering mode also has some problems, such as the incomplete existing software system and the lack of data platform construction. In the future, with the continuous development of 3DP, the compatibility and accuracy of BIM software should be further improved, and a tendering database platform should be established.

The proposed framework of the near-future directions of 3DP in construction is shown in Figure 5.

\section{Conclusions}

This study employed a holistic review process, including a quantitative and qualitative study. Source journals, author analysis, and keyword analysis were included in the quantitative study. The journal with the most articles published among the included journals was Construction and Building Materials, while Automation in Construction was the most cited journal. And the researcher Tan was found to have published the largest number of papers. The keywords were divided into technical dimensions (materials and processes) and nontechnical dimensions (such as design). The qualitative study was conducted on technical and nontechnical dimensions. Two aspects of technical research status were presented, including materials (cementitious materials, polymer materials, and metal materials) and processes (contour crafting, D-shape, concrete printing, and shotcrete $3 \mathrm{D}$ printing). In addition, nontechnical challenges and trends were proposed from economic (mass customization, financial performance over the life cycle), environmental (LCA and BIM), social (health and safety, sustainable 
employment), and legislative (intellectual property, construction standards) aspects.

For theoretical implications, this study establishes a theoretical framework for future development based on current research areas, research themes, and research trends, which provides valuable information to researchers on how to assess the application degree, application necessity, and development direction. This study offers scientific insights and directives to researchers, deepens the understandings of the current technical research status, and fills in the gap of nontechnical challenges. In consideration of the practical implications, this study provides references for practitioners on existing processes, materials, and further application trends of 3DP in construction and improves the preparation of practitioners prior to application.

As the data in the WOS database were the sole source for the research information, the results may be affected by the inherent nature of the publications included in the data set. Additionally, some types of academic publications, such as books or conference papers, were not included due to software limitations. For the development of 3DP in construction, a more comprehensive and in-depth discussion is required, such as research from the perspective of sustainability.

\section{Data Availability}

The data used to support the findings of this study are available from the corresponding author upon request.

\section{Conflicts of Interest}

The authors declare that there are no conflicts of interest regarding the publication of this paper.

\section{Acknowledgments}

This study was supported by the National Natural Science Foundation of China (grant nos. 71971045 and 71801007), MOE (Ministry of Education of China) Project of $\mathrm{Hu}-$ manities and Social Sciences (grant no. 18YJCZH188), and Fundamental Research Funds for the Central Universities (grant no. YWF-20-BJ-W-226).

\section{References}

[1] S. H. Huang, P. Liu, A. Mokasdar, and L. Hou, "Additive manufacturing and its societal impact: a literature review," International Journal of Advanced Manufacturing Technology, vol. 67, no. 5-8, pp. 1191-1203, 2013.

[2] A. Kazemian, X. Yuan, E. Cochran, and B. Khoshnevis, "Cementitious materials for construction-scale 3D printing: laboratory testing of fresh printing mixture," Construction and Building Materials, vol. 145, pp. 639-647, 2017.

[3] T. D. Ngo, A. Kashani, G. Imbalzano, K. T. Q. Nguyen, and D. Hui, "Additive manufacturing (3D printing): a review of materials, methods, applications and challenges," Composites Part B: Engineering, vol. 143, pp. 172-196, 2018.

[4] M. Xia, B. Nematollahi, and J. Sanjayan, "Printability, accuracy and strength of geopolymer made using powder-based
3D printing for construction applications," Automation in Construction, vol. 101, pp. 179-189, 2019.

[5] G. D. Schutter, K. Lesage, V. Mechtcherine, V. N. Nerella, G. Habert, and I. Agustí-Juan, “"Vision of 3D printing with concrete-technical, economic and environmental potentials," Cement and Concrete Research, vol. 12, pp. 25-36, 2018.

[6] T. T. Le, S. A. Austin, S. Lim, R. A. Buswell, A. G. F. Gibb, and T. Thorpe, "Mix design and fresh properties for high-performance printing concrete," Materials and Structures, vol. 45, no. 8, pp. 1221-1232, 2012.

[7] S. Lim, R. A. Buswell, T. T. Le, S. A. Austin, A. G. F. Gibb, and T. Thorpe, "Developments in construction-scale additive manufacturing processes," Automation in Construction, vol. 21, pp. 262-268, 2012.

[8] R. He, M. Li, V. J. L. Gan, and J. Ma, "BIM-enabled computerized design and digital fabrication of industrialized buildings: a case study," Journal of Cleaner Production, vol. 278, Article ID 123505, 2021.

[9] M. H. Ali, A. Abilgaziyev, and D. Adair, "4D printing: a critical review of current developments, and future prospects," International Journal of Advanced Manufacturing Technology, vol. 18, pp. 120-129, 2019.

[10] J. Pegna, "Exploratory investigation of solid freeform construction," Automation in Construction, vol. 5, no. 5, pp. 427-437, 1997.

[11] D. G. Soltan and V. C. Li, "A self-reinforced cementitious composite for building-scale 3D printing," Cement and Concrete Composites, vol. 90, pp. 1-13, 2018.

[12] S. C. Paul, Y. W. D. Tay, B. Panda, and M. J. Tan, "Fresh and hardened properties of 3D printable cementitious materials for building and construction," Archives of Civil and Mechanical Engineering, vol. 18, no. 1, pp. 311-319, 2018.

[13] Y. Ju, L. Wang, H. Xie et al., "Visualization of the three-dimensional structure and stress field of aggregated concrete materials through 3D printing and frozen-stress techniques," Construction and Building Materials, vol. 143, pp. 121-137, 2017.

[14] B. Panda, S. C. Paul, L. J. Hui, Y. W. D. Tay, and M. J. Tan, "Additive manufacturing of geopolymer for sustainable built environment," Journal of Cleaner Production, vol. 167, pp. 281-288, 2017.

[15] Y. Yao, M. M. Hu, F. D. Maio, and S. Cucurachi, "Life cycle assessment of 3D printing geo-polymer concrete," Journal of Industrial Ecology, vol. 24, pp. 1-12, 2019.

[16] C. Buchanan and L. Gardner, "Metal 3D printing in construction: a review of methods, research, applications, opportunities and challenges," Engineering Structures, vol. 180, pp. 332-348, 2019.

[17] T. DebRoy, H. L. Wei, J. S. Zuback et al., "Additive manufacturing of metallic components-process, structure and properties," Progress in Materials Science, vol. 92, pp. 112-224, 2018.

[18] W. E. Frazier, "Metal additive manufacturing: a review," Journal of Materials Engineering and Performance, vol. 23, no. 6, pp. 1917-1928, 2014.

[19] B. Khoshnevis, "Automated construction by contour craftingrelated robotics and information technologies," Automation in Construction, vol. 13, no. 1, pp. 5-19, 2004.

[20] C. Gosselin, R. Duballet, P. Roux, N. Gaudillière, J. Dirrenberger, and P. Morel, "Large-scale 3D printing of ultra-high performance concrete-a new processing route for architects and builders," Materials \& Design, vol. 100, pp. 102-109, 2016. 
[21] I. Perkins and M. Skitmore, "Three-dimensional printing in the construction industry: a review," International Journal of Construction Management, vol. 15, no. 1, pp. 1-9, 2015.

[22] D. D. Camacho, P. Claytona, W. J. O. Brien et al., "“Applications of AM in the construction industry-a forwardlooking review," Automation in Construction, vol. 89, pp. 110-119, 2018.

[23] K. C. Nguyen, P. Tran, and H. X. Nguyen, "Multi-material topology optimization for additive manufacturing using polytree-based adaptive polygonal finite elements," Automation in Construction, vol. 99, pp. 79-90, 2019.

[24] J. Yeon, J. Kang, and W. Yan, "Spall damage repair using 3D printing technology," Automation in Construction, vol. 89, pp. 266-274, 2018.

[25] F. Bos, R. Wolfs, Z. Ahmed, and T. Salet, "Additive manufacturing of concrete in construction: potentials and challenges of 3D concrete printing," Virtual and Physical Prototyping, vol. 11, no. 3, pp. 209-225, 2016.

[26] P. Wu, J. Wang, and X. Wang, "A critical review of the use of 3 -D printing in the construction industry," Automation in Construction, vol. 68, pp. 21-31, 2016.

[27] N. Labonnote, A. Rønnquist, B. Manum, and P. Rüther, "Additive construction: state-of-the-art, challenges and opportunities," Automation in Construction, vol. 72, pp. 347366, 2016.

[28] Y. W. D. Tay, B. Panda, S. C. Paul, N. A. Noor Mohamed, M. J. Tan, and K. F. Leong, "3D printing trends in building and construction industry: a review," Virtual and Physical Prototyping, vol. 12, no. 3, pp. 261-276, 2017.

[29] S. H. Ghaffar, J. Corker, and M. Fan, "Additive manufacturing technology and its implementation in construction as an ecoinnovative solution," Automation in Construction, vol. 93, pp. 1-11, 2018.

[30] A. Siddika, M. A. A. Mamun, W. Ferdous, A. K. Saha, and R. Alyousef, "3D-printed concrete: applications, performance, and challenges," Journal of Sustainable Cement-Based Materials, vol. 9, no. 3, pp. 127-164, 2020.

[31] X. Zhao, "A scientometric review of global BIM research: analysis and visualization," Automation in Construction, vol. 80, pp. 37-47, 2017.

[32] D. Lee, H. Kim, J. Sim, D. Lee, H. Cho, and D. Hong, “Trends in $3 \mathrm{D}$ printing technology for construction automation using text mining," International Journal of Precision Engineering and Manufacturing, vol. 20, no. 5, pp. 871-882, 2019.

[33] R. Jin, B. Zhong, L. Ma, A. Hashemi, and L. Ding, "Integrating BIM with building performance analysis in project life-cycle," Automation in Construction, vol. 106, Article ID 102861, 2019a.

[34] W. W. Hood and C. S. Wilson, "The literature of bibliometrics, scientometrics, and informetrics," Scientometrics, vol. 52, no. 2, pp. 291-314, 2011.

[35] C. M. Chen, "Science mapping: A systematic review of the literature," Walter De Gruyter, vol. 2, no. 2, pp. 1-40, 2017.

[36] A. Darko, A. P. C. Chan, X. Huo, and D.-G. Owusu-Manu, "A scientometric analysis and visualization of global green building research," Building and Environment, vol. 149, pp. 501-511, 2019.

[37] L. C. Freeman, "A set of measures of centrality based on betweenness," Sociometry, vol. 40, no. 1, pp. 35-41, 1977.

[38] R. Jin, P. X. W. Zou, P. Piroozfar et al., "A science mapping approach based review of construction safety research," Safety Science, vol. 113, pp. 285-297, 2019 b.

[39] V. Mechtcherine, V. N. Nerella, F. Will, M. Näther, J. Otto, and M. Krause, "'Large-scale digital concrete
construction-CONPrint3D concept for on-site, monolithic 3D-printing," Automation in Construction, vol. 107, Article ID 102933, 2019.

[40] Y. Weng, M. Li, D. Zhang, M. J. Tan, and S. Qian, "Investigation of interlayer adhesion of 3D printable cementitious material from the aspect of printing process," Cement and Concrete Research, vol. 143, Article ID 106386, 2021.

[41] Y. Weng, M. Li, T. N. Wong, and M. J. Tan, "Synchronized concrete and bonding agent deposition system for interlayer bond strength enhancement in 3D concrete printing," $A u$ tomation in Construction, vol. 123, Article ID 103546, 2021.

[42] Z. Liu, M. Li, Y. W. D. Tay, Y. Weng, T. N. Wong, and M. J. Tan, "Rotation nozzle and numerical simulation of mass distribution at corners in 3D cementitious material printing," Additive Manufacturing, vol. 34, Article ID 101190, 2020.

[43] Z. Liu, M. Li, Y. Weng, Y. Qian, T. N. Wong, and M. J. Tan, "Modelling and parameter optimization for filament deformation in $3 \mathrm{D}$ cementitious material printing using support vector machine," Composites Part B: Engineering, vol. 193, Article ID 108018, 2020.

[44] Y. Weng, M. Li, M. J. Tan, and S. Qian, "Design 3D printing cementitious materials via Fuller Thompson theory and Marson-Percy model," Construction and Building Materials, vol. 163, pp. 600-610, 2018.

[45] P. Zhang, S. Han, S. Ng, and X. H. Wang, "Advanced cementitious building materials with applications incivil engineering," Advances in Civil Engineering, vol. 2017, Article ID 9654910, 3 pages, 2017.

[46] A. Bhardwaj, S. Z. Jones, N. Kalantar et al., "Additive manufacturing processes for infrastructure construction: a review," Journal of Manufacturing Science and Engineering, vol. 141, Article ID 091010, 2019.

[47] Z. Liu, M. Li, Y. Weng, T. N. Wong, and M. J. Tan, "Mixture Design Approach to optimize the rheological properties of the material used in 3D cementitious material printing," Construction and Building Materials, vol. 198, pp. 245-255, 2019.

[48] I. Agustí-Juan and G. Habert, "Environmental design guidelines for digital fabrication," Journal of Cleaner Production, vol. 142, pp. 2780-2791, 2017.

[49] Z. Ding, S. Liu, L. Liao, and L. Zhang, "A digital construction framework integrating building information modeling and reverse engineering technologies for renovation projects," Automation in Construction, vol. 102, pp. 45-58, 2019.

[50] Y. W. Weng, N. A. N. Mohamed, B. J. S. Lee et al., "Extracting BIM information for lattice tool path planning in digital concrete printing with developed dynamo script: a case study," Journal of Computing in Civil Engineering, vol. 35, no. 3, 2021.

[51] I. Kothman and N. Faber, "How 3D printing technology changes the rules of the game," Journal of Manufacturing Technology Management, vol. 27, no. 7, pp. 932-943, 2016.

[52] W.-J. Long, J.-L. Tao, C. Lin et al., "Rheology and buildability of sustainable cement-based composites containing microcrystalline cellulose for 3D-printing," Journal of Cleaner Production, vol. 239, Article ID 118054, 2019.

[53] Y. Weng, S. Ruan, M. Li et al., "Feasibility study on sustainable magnesium potassium phosphate cement paste for 3D printing," Construction and Building Materials, vol. 221, pp. 595-603, 2019.

[54] C. C. Sun, J. C. Xiang, M. X. Xu, Y. He, Z. F. Tong, and X. M. Cui, "3D extrusion free forming of geopolymer composites: materialsmodification and processing optimization," Journal of Cleaner Production, vol. 258, Article ID 120986, 2020. 
[55] B. Huang and S. B. Singamneni, "Curved layer adaptive slicing (CLAS) for fused deposition modelling," Rapid Prototyping Journal, vol. 21, no. 4, pp. 354-367, 2015.

[56] Y. Weng, M. Li, Z. Liu et al., "Printability and fire performance of a developed $3 \mathrm{D}$ printable fibre reinforced cementitious composites under elevated temperatures," Virtual and Physical Prototyping, vol. 14, no. 3, pp. 284-292, 2018.

[57] S. C. Paul, P. A. G. Gideon van Zij, M. J. Tan, and I. Gibson, "A review of $3 \mathrm{D}$ concrete printing systems and materials properties: current status and future research prospects," Rapid Prototyping Journal, vol. 24, pp. 784-798, 2016.

[58] O. Davtalab, A. Kazemian, and B. Khoshnevis, "Perspectives on a BIM-integrated software platform for robotic construction through Contour Crafting," Automation in Construction, vol. 89, pp. 13-23, 2018.

[59] B. Lu, Y. Qian, M. Li et al., "Designing spray-based 3D printable cementitious materials with fly ash cenosphere and air entraining agent," Construction and Building Materials, vol. 211, pp. 1073-1084, 2019.

[60] B. Lu, W. Zhu, Y. Weng et al., "Study of MgO-activated slag as a cementless material for sustainable spray-based 3D printing," Journal of Cleaner Production, vol. 258, Article ID 120671, 2020.

[61] H. Kloft, H.-W. Krauss, N. Hack et al., "Influence of process parameters on the interlayer bond strength of concrete elements additive manufactured by Shotcrete 3D Printing (SC3DP)," Cement and Concrete Research, vol. 134, Article ID 106078, 2020.

[62] P. Shakor, J. Sanjayan, A. Nazari, and S. Nejadi, "Modified 3D printed powder to cement-based material and mechanical properties of cement scaffold used in 3D printing," Construction and Building Materials, vol. 138, pp. 398-409, 2017.

[63] R. A. Buswell, A. Thorpe, R. C. Soar, and A. G. F. Gibb, "Design, data and process issues for mega-scale rapid manufacturing machines used for construction," Automation in Construction, vol. 17, no. 8, pp. 923-929, 2008.

[64] X. Zhang, M. Li, J. H. Lim et al., "Large-scale 3D printing by a team of mobile robots," Automation in Construction, vol. 95, pp. 98-106, 2018.

[65] J. H. Lim, Y. Weng, and Q.-C. Pham, "3D printing of curved concrete surfaces using Adaptable Membrane Formwork," Construction and Building Materials, vol. 232, Article ID 117075, 2020.

[66] W. H. Tan and P. F. Wang, "Experimental study on seepage properties of jointed rock-likesamples based on 3D printing techniques," Advances in Civil Engineering, vol. 2020, Article ID 9403968, 10 pages, 2020.

[67] G. Cesaretti, E. Dini, X. De Kestelier, V. Colla, and L. Pambaguian, "Building components for an outpost on the Lunar soil by means of a novel 3D printing technology," Acta Astronautica, vol. 93, pp. 430-450, 2014.

[68] Y. Weng, M. Li, S. Ruan et al., "Comparative economic, environmental and productivity assessment of a concrete bathroom unit fabricated through $3 \mathrm{D}$ printing and a precast approach," Journal of Cleaner Production, vol. 261, Article ID 121245, 2020.

[69] D. Rejeski, F. Zhao, and Y. Huang, "Research needs and recommendations on environmental implications of additive manufacturing," Additive Manufacturing, vol. 19, pp. 21-28, 2010.

[70] G. H. Brundtland, Our Common Future, Oxford University Press, Oxford, UK, 1987.

[71] M. R. M. Saade, A. Yahia, and B. Amor, "How has LCA been applied to $3 \mathrm{D}$ printing? A systematic literature review and recommendations for future studies," Journal of Cleaner Production, vol. 244, Article ID 118803, 2019.

[72] H. Alhumayani, M. Gomaa, V. Soebarto, and W. Jabi, "Environmental assessment of large-scale 3D printing in construction: a comparative study between cob and concrete," Journal of Cleaner Production, vol. 270, Article ID 122463, 2020.

[73] Y. Han, Z. Yang, T. Ding, and J. Xiao, "Environmental and economic assessment on 3D printed buildings with recycled concrete," Journal of Cleaner Production, vol. 278, Article ID 123884, 2021.

[74] C. Moreno, S. Olbina, and R. R. Issa, "BIM use by architecture, engineering, and construction (AEC)industry in educational facility projects," Advances in Civil Engineering, vol. 2019, Article ID 1392684, 19 pages, 2019.

[75] F. M. Rivera, J. C. Vielma, R. F. Herrera, and J. Carvallo, "Methodology for building information modeling (BIM) implementation in structural engineering companies (SECs)," Advances in Civil Engineering, vol. 2019, Article ID 8452461, 16 pages, 2019.

[76] F. Rodrigues, J. Teixeira, R. Matos, and H. Rodrigues, "Development of a web application for historical buildingmanagement through BIM technology," Advances in Civil Engineering, vol. 2019, Article ID 9872736, 15 pages, 2019.

[77] M. Baumers, J. R. Duflou, W. Flanagan, T. G. Gutowski, K. Kellens, and R. Lifset, "Charting the environmental dimensions of additive manufacturing and 3D printing," Journal of Industrial Ecology, vol. 21, no. S1, pp. S9-S14, 2017.

[78] B. Ilhan and B. Yobas, "Measuring construction for social, economic and environmental assessment," Engineering, Construction and Architectural Management, vol. 26, no. 5, pp. 746-765, 2019.

[79] H. K. Chan, J. Griffin, J. J. Lim, F. Zeng, and A. S. F. Chiu, "The impact of $3 \mathrm{D}$ printing technology on the supply chain: manufacturing and legal perspectives," International Journal of Production Economics, vol. 205, pp. 156-162, 2018.

[80] W. Gao, Y. Zhang, D. Ramanujan et al., "The status, challenges, and future of additive manufacturing in engineering," Computer-Aided Design, vol. 69, pp. 65-89, 2015.

[81] X. Y. Zhao, Q. L. Lian, Z. X. He, and S. Y. Zhang, "Regionbased online flaw detection of $3 \mathrm{D}$ printing via fringe projection," Measurement Science and Technology, vol. 31, no. 3, 2019. 